\title{
Contextualism and radical scepticism
}

\author{
Duncan Pritchard ${ }^{1}$
}

Received: 18 January 2016/ Accepted: 10 May 2016 / Published online: 21 May 2016 (C) The Author(s) 2016. This article is published with open access at Springerlink.com

\begin{abstract}
A critique of attributer contextualist treatments of the problem of radical scepticism is offered. It is argued that while such proposals, standardly conceived, gain some purchase against the closure-based formulation of this problem, they run aground when applied to the logically distinct underdetermination-based formulation. A specific kind of attributer contextualism-rational support contextualism-is then explored. This is better placed to deal with underdetermination-based radical scepticism via its endorsement of ascriptions of factive rational support in everyday contexts of epistemic appraisal. But such a proposal is faced with a dialectical impasse with regard to the competing epistemological disjunctivist response to radical scepticism. While the former has dialectical advantages over the latter with regard to closurebased radical scepticism, the latter has the dialectical upper-hand when it comes to underdetermination-based radical scepticism. It is claimed that the way to resolve this issue - and thereby to understand that we should not expect a unified treatment of these two formulations of the sceptical problem, much less one that is cast along contextualist lines-is to recognise how these two formulations reflect distinct sources of scepticism.
\end{abstract}

Keywords Radical scepticism · Contextualism · Epistemological disjunctivism · Wittgenstein

\section{Contra attributer contextualist anti-scepticism}

One of the most influential treatments of the problem of radical scepticism in recent years has been that offered by attributer contextualism. According to this proposal, 'knows' is a context-sensitive term, such that the truth-value of an assertion of a sen-

\footnotetext{
$凶$ Duncan Pritchard

duncan.pritchard@ed.ac.uk

1 University of Edinburgh, Edinburgh, UK
} 
tence of the form ' $S$ knows that $p$ '-call this a knowledge ascription sentence-can be dependent upon in which conversational context the sentence is uttered (i.e., the context of the attributer). More precisely, the kind of attributer contextualism that concerns us posits that 'knows' can pick out more or less demanding epistemic standards in different conversational contexts. Thus, in a conversational context that incorporates a demanding epistemic standard for 'knows', someone could assert a knowledge ascription sentence and thereby speak falsely, even though, in a different conversational context (i.e., one which incorporates a less demanding epistemic standard), the assertion of this very same ascription sentence could express a truth. ${ }^{1}$

The potential import of this way of thinking about 'knows' to the problem of radical scepticism ought to be clear. Perhaps when the sceptic denies that we have knowledge she speaks truly, but only because her assertions of the negated form of the knowledge ascription sentences (i.e., 'S doesn't know that $p$ ') are made relative to a conversational context that employs a very demanding epistemic standard. In contrast, in normal conversational contexts where radical sceptical considerations are not at issue, when subjects' assert the corresponding (non-negated) knowledge ascription sentences they also speak truly, because these assertions are made relative to a conversational context which employs an undemanding epistemic standard. In this way, we can contend that the two camps are in effect 'talking past' one another. ${ }^{2}$

Arguably, at any rate, there are precedents for this kind of phenomenon in our ordinary language. Whether something counts as 'tall', 'short', 'flat', 'empty', and so on, can be determined by conversational context, such that a sentence ascribing this property to something can express a truth relative to one conversional context and a falsehood relative to another. So, for example, someone talking about John, who is over six feet tall, in a normal conversational context could assert 'John is tall' and thereby speak truly, since the standards for tallness operative in this context are relatively undemanding. In contrast, in a conversational context that has more demanding standards for tallness-e.g., where the coaches for the basketball team are discussing their options-someone could assert 'John is tall' and speak falsely. If this is possible for predicates like 'tall', then why not 'knows'?

Attributer contextualism can feel like a very natural response to the problem of radical scepticism, since when one first engages with this difficulty it does tend to strike one as trading on some sort of illicit raising of the epistemic standards. Moreover, on the face of it anyway, attributer contextualism offers an elegant response to the

\footnotetext{
${ }^{1}$ For some of the key defences of attributer contextualism, see DeRose (1995), Lewis (1996), and Cohen (2000).

2 That's not quite right, of course, in that in order to 'talk past' someone one (usually, anyway) has to at least be talking with them, and the contrast we just drew was between a sceptical conversational context and a normal, non-sceptical conversational content-i.e., two distinct conversational contexts. Still, the general idea that the radical sceptical problem on this view trades on a misunderstanding-i.e., on something purely semantic—should be clear.

${ }^{3}$ Note that in what follows I will talk not of conversational contexts specifically (although this is the usual terminology employed by attributer contextualists), but rather more generally of contexts of epistemic appraisal (which leaves it open whether such contexts need to be specifically conversational). Nothing hangs on this shift of terminology for our purposes (indeed, arguably it makes the attributer contextualist position more palatable). See also endnote 10.
} 
radical sceptical problem. Indeed, attributer contextualism seems to present us with an undercutting response to this problem, such that it offers us a philosophical basis on which we can plausibly maintain that this putative paradox is in fact bogus (i.e., as opposed to an overriding response to the problem, which grants that the paradox is genuine but offers a revisionary solution). ${ }^{4}$ That is, attributer contextualists seem to be in a position to argue that radical scepticism only looks like a bona fide paradox because of a failure to appreciate the context-sensitivity of 'knows'.

Consider the standard, closure-based, way of expressing the sceptical problem in the contemporary literature. For our purposes, we will focus our attention on rationally grounded knowledge, in order to side-step issues that might arise with knowledge that lacks a rational grounding. ${ }^{5}$ In order to simplify things, we will formulate the sceptical problem as it concerns an agent's rationally grounded knowledge of an 'everyday' empirical proposition ('E'), the kind of proposition which is typically thought to be known, and where the belief in question is regarded as rationally grounded. If one has rationally grounded knowledge of these everyday empirical propositions, then the challenge posed by radical scepticism is illusory. We will also focus on a specific radical sceptical hypothesis which is by stipulation incompatible with E-viz., the hypothesis that, unbeknownst to one, one is a brain-in-a-vat (BIV) being 'fed' one's experiences by supercomputers.

With these stipulations in mind, here is the closure-based radical sceptical paradox:

\section{The closure-based radical sceptical paradox}

$\left(\mathrm{S}_{1} 1\right)$ One cannot have rationally grounded knowledge that one is not a BIV.

$\left(\mathrm{S}_{1} 2\right)$ If one cannot have rationally grounded knowledge that one is not a BIV, then one cannot have rationally grounded knowledge that $\mathrm{E}$.

$\left(\mathrm{S}_{1} 3\right)$ I have rationally grounded knowledge that E. ${ }^{6}$

$\left(S_{1} 1\right)$ is motivated by the general thought that one cannot have rationally grounded knowledge that one is not the victim of a radical sceptical hypothesis. Given that, ex hypothesi, one cannot distinguish between one's ordinary experiences and the corresponding experiences that one would have if one were a BIV, then how could one have a rational basis for knowing that one is not a BIV? ${ }^{7}\left(\mathrm{~S}_{1} 3\right)$ is motivated by the general anti-sceptical thought noted above that E-type propositions are widely known, where this knowledge is rationally grounded.

\footnotetext{
${ }^{4}$ For a recent discussion of the distinction between undercutting and overriding anti-sceptical strategies, and its dialectical significance, see Pritchard (2015, part one).

5 For further discussion of why the sceptical problem is best understood in terms of rationally grounded knowledge, see Pritchard (2015, part one).

6 Note that this formulation of radical scepticism is in fact much stronger than we need to generate the sceptical paradox. In particular, in terms of $\left(S_{1} 1\right)$, it would suffice, for example, that one does not-as opposed to the stronger cannot-have rationally grounded knowledge that one is not a BIV. Relatedly, it would suffice for $\left(S_{1} 2\right)$ that it follows from one's lack of rationally grounded knowledge that one is not a BIV that one lacks rationally grounded knowledge that $\mathrm{E}$.

7 Note that in order to keep matters simple I am setting to one side those responses to radical scepticisme.g., Vogel (1990) — which claim that we have an abductive rational basis for preferring our everyday beliefs over sceptical alternatives. I critically discuss such a proposal in Pritchard (2015, ch. 1).
} 
That leaves us with the second claim, $\left(\mathrm{S}_{1} 2\right)$. This is motivated by appeal to the following principle:

\section{The closure principle}

If $S$ has rationally grounded knowledge that $p$, and $S$ competently deduces from $p$ that $q$, thereby forming a belief that $q$ on this basis while retaining her rationally grounded knowledge that $p$, then $S$ has rationally grounded knowledge that $q$.

With the closure principle in play, it follows that if one did have rationally grounded knowledge that $\mathrm{E}$, then one could competently deduce from this knowledge that one is not a BIV, and thereby acquire rationally grounded knowledge that one is not a BIV. ${ }^{8}$ Conversely, if it is already granted that one simply cannot have rationally grounded knowledge that one is not a BIV, it follows that one cannot have rationally grounded knowledge that $\mathrm{E}$ either. We thus get $\left(\mathrm{S}_{1} 2\right)$.

The guiding thought behind the closure principle is that competent deduction is a paradigm instance of a rational process. Accordingly, any belief which is grounded on a competent deduction from rationally grounded knowledge-and where the original rationally grounded knowledge is preserved throughout the deduction-cannot be itself any less rationally grounded. There are, of course, weaker formulations of closure-style principles in this general vein in the literature, and some of them have been rejected for various reasons. ${ }^{9}$ But it is hard to see how one could motivate a rejection of the principle as just formulated, which is why the debate about closure-based radical scepticism is now generally targeted on this specific formulation. How could one have rationally grounded knowledge, competently deduce a belief on this basis (while retaining the original rationally grounded knowledge), and yet lack rationally grounded knowledge of the proposition deduced? At the very least, any anti-sceptical strategy that proceeds by rejecting this principle will face a steep up-hill task.

Since the three claims that make up this paradox are in logical conflict with one another, so we know that at least one of them must be false, where radical scepticism qua position rather than paradox would be the view that rejects $\left(\mathrm{S}_{1} 3\right)$. But since all three claims are highly intuitive, or at least supported by highly intuitive claims (such as the closure principle), it is hard to see which is to go. Indeed, what we seem to have here is an inconsistent triad, where each of the theses that make up this triad as highly intuitive:

\section{The inconsistent radical sceptical triad}

(I) One is unable to have rationally grounded knowledge of the denials of radical sceptical hypotheses.

(II) The closure principle.

(III) One has widespread rationally grounded everyday knowledge.

\footnotetext{
8 Note that here, and in what follows, we are taking it as given that one knows that E entails that one is not a BIV.

9 In particular, the most famous rejections of closure-style principles as a means of blocking radical scepticism—due to Dretske (1970) and Nozick (1981) - have been concerned with much weaker formulations of the closure principle, and hence do not straightforwardly apply to the closure principle as we have formulated it here. For a useful recent exchange on the status of closure-style principles, see Dretske (2005a, b) and Hawthorne (2005).
} 
Attributer contextualism seems to offer us a route out of this problem by highlighting how we are in a sense jumping back and forth between distinct contexts of epistemic appraisal. Prior to engaging with the sceptical problem, and thus considering sceptical hypotheses, there is nothing amiss with endorsing (III), and of course in this context of epistemic appraisal one doesn't even consider the status of (I). But once one undertakes closure-style inferences involving the denials of radical sceptical hypotheses, then one enters a context of epistemic appraisal in which one will no longer ascribe knowledge in line with (III), and hence there is no tension between (III) and one's endorsement, in this context, of (I). The attributer contextualist can thus, it seems, happily endorse the closure principle, and thus (II), because there is no single context of epistemic appraisal where she is committed to endorsing both of the other two claims that make up the inconsistent triad. ${ }^{10}$

So construed, attributer contextualism plausibly offers us an undercutting antisceptical strategy. In particular, it presents us with a way of thinking about the putative sceptical paradox such that it is illusory, in that it trades on an illicit assumption that there is no shift in the context of epistemic appraisal taking place. Moreover, notice that this way of dealing with the radical sceptical problem at least concedes something to the sceptic, and hence can potentially explain why we were taken in by this puzzle in the first place. After all, on this view radical scepticism is correct in the context of epistemic appraisal in which the problem is posed. That is, the attributer contextualist 'resolution' of the radical sceptical problem effectively involves conceding, in the philosophical context of epistemic appraisal in which one engages with this problem, that the sentences that the radical sceptic asserts regarding our epistemic position express truths. It is thus no wonder that we get taken in by this problem, since whenever we consider it we are thereby in a context of epistemic appraisal in which the sceptic's assertions are true. If the attributer contextualist is right, then the trick is simply to realise that this is only so relative to this specific context of epistemic appraisal. As Keith DeRose (1995, p. 42) has put the point, once "the conversational air has cleared" and one returns to a normal context of epistemic appraisal which employs quotidian epistemic standards, then assertions of knowledge ascription sentences will tend to express truths once more. ${ }^{11}$

Even so, one might be suspicious at the ease with which attributer contextualism disposes of the problem of radical scepticism. For example, if this difficulty simply trades on such a straightforward semantic point, then why has this philosophical

\footnotetext{
10 It is worth flagging here that the attributer contextualist response to the closure-based formulation of radical scepticism is far less plausible if one interprets the closure principle in other, less specific, ways. See Pritchard (2015, part one) for further discussion of this point. Note too the potential importance of our terminological shift from expressing attributer contextualism in terms of conversational contexts to formulating the view in terms of contexts of epistemic appraisal (see endnote 3). After all, in considering radical sceptical hypotheses one might not actually be in a particular conversational context at all, at least where that is understood as something involving actual conversation between two or more people. Still, I think we can charitably interpret attributer contextualism such that whatever applies to conversational contexts will carry over-somehow, the details need not concern us here-into relevantly analogous nonconversational contexts of epistemic appraisal.

11 Actually, I think the idea that the 'conversational air' can simply clear in this way is far from straightforward. This is the so-called 'problem of epistemic descent', as explained in Pritchard (2001). I will be setting this concern to one side in what follows, however.
} 
problem gripped us for so long? Note that there is no parallel difficulty regarding the context-sensitivity of supposedly analogous terms like 'tall' and so forth. No-one is remotely puzzled by the fact that someone can be considered tall in a normal conversational context and yet not be considered tall relative to a specialised conversational context in which higher standards for tallness are operative. So why has a radical sceptical problem arisen regarding our use of 'knows'? Are we radically mistaken about the usage of this everyday term? As a number of commentators have noted, attributer contextualism seems to attribute a degree of semantic blindness to subjects that is independently suspect. ${ }^{12}$

A second problem that afflicts the attributer contextualist response to radical scepticism concerns how it endorses an epistemic hierarchy of contexts. The attributer contextualist concedes that the radical sceptic is employing more demanding epistemic standards for 'knows' than are operative in everyday contexts of epistemic appraisal. But doesn't this effectively cede the epistemological high ground to the radical sceptic? The upshot of attributer contextualism seems to be that if we follow-through on our basic epistemic commitments, then the paradox will disappear for the simple reason that radical scepticism, qua position, will be correct. Our only protection against this eventuality is to blinker ourselves to the radical sceptical context of epistemic appraisal. That is hardly a philosophically satisfying way of dealing with a paradox.

There are other problems facing the attributer contextualist response to radical scepticism, but I want to focus my critique on a particular issue. I want to suggest that any plausibility that this proposal might possess completely disappears once we try to apply this proposal to a different formulation of the sceptical problem, one that trades not on the closure principle, but rather on the underdetermination principle.

\section{Underdetermination-based radical scepticism}

This is the formulation of the underdetermination-based radical sceptical paradox that we will be focussing upon:

\section{The underdetermination-based radical sceptical paradox}

$\left(\mathrm{S}_{2} 1\right)$ One cannot have a rational basis that favours one's belief that E over the BIV scenario.

$\left(\mathrm{S}_{2} 2\right)$ If one cannot have a rational basis that favours one's belief that E over the BIV scenario, then one lacks rationally grounded knowledge that E.

$\left(\mathrm{S}_{2} 3\right)$ I have rationally grounded knowledge that E. ${ }^{13}$

\footnotetext{
12 I believe the first to make this point was Schiffer (1996). Note that this is now part of a cluster of related (semantic/linguistic) objections that are made to attributer contextualism. See, for example, Stanley (2005, ch. 2) on whether 'knows' is a gradable adjective like 'flat' or 'tall' as (some canonical versions of) attributer contextualism suggest. There is also the related issue of whether attributer contextualism correctly describes our everyday practices of asserting knowledge ascription sentences. For further criticism in this direction, see Pritchard (2001, 2005a). For a helpful overview of the contemporary literature regarding both issues, see Rysiew (2011).

13 As with our formulation of the closure-based radical sceptical paradox above-see endnote 6-note that this formulation of radical scepticism is in fact much stronger than we need to generate the sceptical
} 
As with the closure-based formulation of the radical sceptical paradox, these three claims are clearly in logical conflict, and hence we know that at least one of them must be false. The final claim that makes up the underdetermination-based radical sceptical paradox is identical to the final claim that makes up the closure-based radical sceptical paradox, so we can focus our attention on the other two.

The first claim, $\left(\mathrm{S}_{2} 1\right)$, captures a widely held commitment in epistemology to the socalled new evil demon intuition. Consider two agents. The first is in normal epistemic conditions - call this the good case. The second, in contrast, is an identical counterpart of the first but unfortunately the victim of a radical sceptical hypothesis (such as the BIV hypothesis) — call this the bad case. It is by stipulation impossible for either subject to distinguish between their experiences and those had by their counterpart. The new evil demon intuition is the claim that the first agent in the good case cannot have a better rational basis for her beliefs than her counterpart in the bad case does for her corresponding beliefs. After all, given that the good and bad cases are indistinguishable to the subjects concerned, how could the agent in the good case have a better rational standing for her beliefs than her counterpart in the bad case? ${ }^{14}$

The second claim in the underdetermination-based formulation of radical scepticism, $\left(\mathrm{S}_{2} 2\right)$, is meant to be derived from the following underdetermination principle:

\section{The underdetermination principle}

If $S$ knows that $p$ and $q$ describe incompatible scenarios, and yet $S$ lacks a rational basis that favours belief that $p$ over $q$, then $S$ lacks rationally grounded knowledge that $p$.

With this principle in play, it follows that if one lacks a rational basis which favours $\mathrm{E}$ over the BIV alternative, then one lacks rationally support knowledge that E. We thus get $\left(\mathrm{S}_{2} 2\right)$.

The underdetermination principle is meant to be entirely uncontentious. Consider what it would mean for it to be false. This would entail that one could have rationally grounded knowledge of a proposition even while recognising that the proposition believed was incompatible with an alternative scenario and that one's rational basis for one's belief didn't favour it over the alternative scenario. An example might be having rationally grounded knowledge that one is seated even while recognising that one has no better reason for thinking that one is seated than that one is standing (a known to be incompatible alternative). Although there might be some dispute over what is involved in having rationally grounded knowledge, we would surely want a conception of this kind of knowledge such that it excluded this possibility.

But with these three claims in play, we have a paradox on our hands, in that each of these claims is either highly intuitive in its own right, or else-in the case of $\left(\mathrm{S}_{2} 2\right)$ -

Footnote 13 Continued

paradox. In particular, in terms of $\left(\mathrm{S}_{2} 1\right)$, it would suffice, for example, that one does not-as opposed to the stronger cannot-have a rational basis that favours one's belief that E over the BIV scenario. Relatedly, it would suffice for $\left(\mathrm{S}_{2} 2\right)$ that it follows from one's lack of such a favouring rational basis that one lacks rationally grounded knowledge that $\mathrm{E}$.

14 The loci classici as regards the new evil demon intuition are Lehrer and Cohen (1983) and Cohen (1984). I discuss this intuition at length in Pritchard (forthcoming $b$ ). 
can be derived from a further claim which is highly intuitive. Indeed, we can usefully express this paradox in terms of the following inconsistent triad:

The inconsistent radical sceptical triad*

(I*) One cannot have rational support that favours one's belief in an everyday proposition over an incompatible radical sceptical hypothesis.

(II*) The underdetermination principle.

(III*) One has widespread rationally grounded everyday knowledge.

The closure and underdetermination-based formulations of the radical sceptical paradox are clearly very similar. They share a claim, and the sceptical challenge posed in each case is the same. Moreover, they can each be formulated in terms of a conflict between our rationally grounded knowledge of an everyday proposition, E, and an epistemic lack which is exposed by radical sceptical hypotheses, in this case the BIV hypothesis. Crucially, however, these two formulations of the sceptical problem are logically distinct, and this is because the epistemic demands made by the two epistemic principles on which they turn are subtly different.

We can evaluate the relative logical strengths of these two epistemic principles by considering, in a simplified and analogous fashion, what each principle demands in the particular case of a subject's belief that E in the context of the BIV sceptical hypothesis:

\section{The simplified closure-based entailment}

If $S$ has rationally grounded knowledge that $\mathrm{E}$, then $S$ has rationally grounded knowledge that she is not a BIV.

\section{The simplified underdetermination-based entailment}

If $S$ has rationally grounded knowledge that E, then $S$ has rational support for her belief that $\mathrm{E}$ which favours that belief over the sceptical alternative that she is a BIV.

I take it that the simplified closure-based entailment is an obvious, and uncontentious, simplification of what the closure principle demands in this case. That the simplified underdetermination-based entailment is a simplification of what the underdetermination principle demands is not so obvious, but that is because we are effectively working with a contraposed version of the principle. Uncontraposed, the entailment would be that if one lacks a rational basis which favours belief that E over the alternative sceptical scenario that one is a BIV, then one lacks rationally grounded knowledge that E. The reason why it is useful to work with a contraposed version of this claim is that the underdetermination-based entailment will then share its antecedent with the simplified closure-based entailment. We can thus focus our attention on what is entailed in each case.

With the entailments generated by the underdetermination and closure principles simplified in this way, we can detect one obvious difference between them. This is that whereas the simplified closure-based entailment demands that one has rationally grounded knowledge that one is not a BIV, the simplified underdetermination-based entailment merely demands that one has a rational basis that favours one's belief that E over the BIV alternative. The former claim is much more demanding than the latter 
claim, in that one can have better reasons for believing E rather than the BIV hypothesis without thereby possessing rationally grounded knowledge that one is not a BIV. In particular, while having better reason to believe that E as opposed to the BIV hypothesis plausibly entails that one has some reason for believing that one is not a BIV, it would be a stretch to maintain that this by itself entails that one has rationally grounded knowledge that one is not a BIV (even granted that the entailed belief in question will be true). There is thus a strong prima facie basis for arguing that the underdetermination principle is logically weaker than the closure principle, in the sense that from the same antecedent the former principle extracts a logically weaker consequent.

This point is confirmed once we reflect on the logical relationships in the other direction-viz., from the closure principle to the underdetermination principle. For notice that if one has rationally grounded knowledge that $\mathrm{E}$, and one thereby has rationally grounded knowledge, via the closure principle, that one is not a BIV, then of course one inevitably has a rational basis which favours belief that E over the alternative sceptical scenario that one is a BIV. One has, after all, rationally grounded knowledge that one is not a BIV. The closure principle is thus more demanding than the underdetermination principle.

What this means for our dealings with the two formulations of the sceptical argument is not straightforward, since it depends on what anti-sceptical strategy one opts for. For example, if one were to approach underdetermination-based scepticism by denying the underdetermination principle, then that would obviously suggest a response to closure-based scepticism which involved denying the closure principle. But if one opts to retain the underdetermination principle, then there would be various options available for dealing with closure-based scepticism. In any case, the crux of the matter is that we need to be sensitive to the subtle differences between these formulations of scepticism.

Now that we recognise that these two formulations of radical scepticism are distinct, we can ask how the attributer contextualist response to the closure-based formulation that we examined above translates to the underdetermination-based formulation. As we will see, this is the point at which attributer contextualism gets into seriously difficulties.

The roots of the problem I have in mind here are apparent even in the response that attributer contextualism offers to closure-based radical scepticism. Take the formulation of this problem specifically in terms of rationally grounded knowledge that we explored above. According to attributer contextualism, in everyday contexts of epistemic appraisal in which knowledge ascription sentences are asserted-sentences that presumably typically concern rationally grounded knowledge-these assertions express truths. Thus the attributer contextualist contends that she doesn't need to reject (III), at least not in any way that would lend support to radical scepticism.

But of course the million-dollar question that one wants to ask at this juncture is what it is in virtue of that one possesses this rationally grounded knowledge of everyday propositions, given that one lacks a rational basis for ruling out radical sceptical hypotheses. Since attributer contextualism is first and foremost a theory about 'knows', and thus knowledge ascriptions, rather than an epistemological proposal, it is perhaps inevitable that it tends to be silent on this question. And yet without a plausible story in this regard the entire anti-sceptical credentials of attributer contextualism are in doubt. 
We can bring this point into sharper relief by applying the attributer contextualist anti-sceptical line to the inconsistent triad at issue in underdetermination-based radical scepticism. Which of these three claims are we to understand the attributer contextualist as denying? Well, clearly not (III*), at least where this concerns the truth of assertions of knowledge ascription sentences in everyday contexts of epistemic appraisal. But again, we might ask, in virtue of what are these assertions true, given that one lacks a rational basis for excluding radical sceptical hypotheses?

In particular, what is the attributer contextualist to say about claims (I*) and (II*)? There is certainly nothing in attributer contextualism that would suggest that it should reject one or both of these principles. This is hardly surprising, given that they are epistemological claims and attributer contextualism is primarily a semantic thesis. Even so, it is not as if there is a natural way of extending the attributer contextualist thesis into the epistemic realm so that it is able to offer a response to this problem. On what principled basis would the attributer contextualist deny either of these claims?

Presumably, the attributer contextualist line will be to focus on (I*). Since this explicitly mentions radical sceptical hypotheses, on this view even to consider such a claim is to put one into a sceptical context of epistemic appraisal in which high epistemic standards apply. So $\left(I^{*}\right)$ is inevitably true whenever one considers it. It is thus little wonder that we think that this claim is true.

For this line of response to gain some purchase on the underdetermination-based sceptical paradox it would need to be supplemented with a further contention to the effect that, relative to normal contexts of epistemic appraisal, the rational support one has for one's beliefs is (for all the radical sceptic has shown anyway) entirely in order. But what would be the source of this claim? There seems nothing in the attributer contextualist approach to radical scepticism that would license such a thesis. And yet without it this particular formulation of the radical sceptical paradox is still standing.

The nub of the matter is that the underdetermination-based sceptical paradox doesn't seem to trade on an appeal to epistemic standards at all, but rather turns on a perfectly general thesis about the inadequacy of the rational support available to us for our everyday beliefs. Since the attributer contextualist lacks the resources to counter this claim, it fails to effectively engage with this sceptical problem.

The upshot of the foregoing is that there is no substitute for an epistemological diagnosis of the radical sceptical paradox. For attributer contextualism to function as an anti-sceptical proposal, it needs to engage with the epistemological theses that generate the paradox. This is especially manifest when it comes to the underdetermination-based radical sceptical paradox, in that attributer contextualism by itself has no story to tell at all about how our everyday knowledge can be rationally grounded given that we lack a rational basis which favours our everyday beliefs over radical sceptical alternatives.

\section{Rational support contextualism}

Thus far we have conceived of attributer contextualism as a thesis directed at ascriptions of knowledge. But suppose we reconceived of the view as being primarily concerned with ascriptions regarding the rational support available for our beliefs? In particular, imagine a form of attributer contextualism that maintained that the 
strength of rational support properly attributable to a subject could vary in response to changes in the context of epistemic appraisal. Relative to everyday contexts of epistemic appraisal, a subject could be truthfully ascribed very strong rational support for her beliefs, but relative to sceptical contexts of epistemic appraisal, in contrast, the very same subject could at best only be truthfully ascribed a very weak level of rational support for her beliefs. In this way one could maintain that the epistemic standards relevant to assessing the truth of assertions of knowledge ascription sentences don't vary from one context of epistemic appraisal to another, but that nonetheless whether or not these assertions express truths is a variable matter. Call such a view rational support contextualism. ${ }^{15}$

This is broadly the view defended by Ram Neta (2002, 2003), although he describes his view in terms of evidence rather than reasons, a difference that we will set to one side here. In particular, Neta defends a view such that in everyday contexts of epistemic appraisal the rational support that can be truthfully ascribed to an agent's belief can be factive, such as it entails the target proposition. For example, one's perceptual belief that $p$ in an everyday context of epistemic appraisal can be regarded as supported by the factive reason that one sees that $p$, where seeing that $p$ entails $p$. What happens on this view when radical scepticism is introduced to the context of epistemic appraisal is that the rational support that can be truthfully ascribed to a subject's beliefs shrinks to being merely non-factive support (e.g., that it seems to one as if p, rather than that one sees that $p$ ). This is why although the epistemic standards for assessing knowledge ascriptions do not change, it is nonetheless the case that assertions of knowledge ascriptions sentences will tend to express truths in everyday contexts of epistemic appraisal and express falsehoods in sceptical contexts of epistemic appraisal. Nonetheless, since one can truthfully ascribe factive rational support to a subject's beliefs in everyday contexts of epistemic appraisal, so rational support contextualism has a straightforward way out of the problem we posed for the attributer contextualist treatment of underdetermination-based radical scepticism above. For on this view, there is a plausible story to be told about how one's beliefs in everyday contexts of epistemic appraisal might amount to rationally grounded knowledge even despite one's inability to rationally exclude radical sceptical hypotheses. After all, the rational support that one can truthfully ascribe to an agent in such a context will actually entail the falsity of these sceptical hypotheses. ${ }^{16}$

Here is Neta's description of this proposal:

Suppose that we are talking on the phone and I claim to know that my basement floor is all wet. You ask me what evidence I have that it's wet, and I reply that I can see that it's wet. Here, my evidence reaches all the way out to the fact: I can't see that my floor is all wet unless it is, in fact, all wet. There is, in this case, no epistemic gap between my evidence and my belief.

\footnotetext{
15 Note that, henceforth, when I refer to 'attributer contextualism' without qualification, I will have the standard version of this view (as described above) in mind, as opposed to the specific form of attributer contextualism that is embodied by rational support contextualism.

16 Note that henceforth we will be taking rational support contextualism to refer to this particular proposal (i.e., the form of rational support contextualism according to which in everyday contexts of epistemic appraisal one can truthfully ascribe factive rational support to a subject's beliefs).
} 
Nonetheless, when we face certain skeptical challenges, we move into a context of epistemic appraisal in which we can truthfully say that our evidence fails to support our beliefs about the external world. Once we are in such a context, we can't find evidence for those beliefs, for none of our mental states count as evidence for such beliefs in that context. Thus, by issuing or confronting skeptical challenges, we create an epistemic gap between our beliefs about that world and our evidence for them. (Neta 2003, p. 27)

Here we get the essentials of the view. Exchanging talk of evidence with talk of reasons, Neta is claiming that relative to everyday contexts of epistemic appraisal the rational support one properly ascribes to a subject's beliefs can be factive, but that relative to sceptical contexts of epistemic appraisal the rational support that one properly ascribes diminishes to the point of being non-factive. This is why, relative to sceptical contexts of epistemic appraisal, the radical sceptic's claim that we lack knowledge expresses a truth (because such non-factive rational support fails to favour our everyday beliefs over radical sceptical alternatives).

By allowing subjects to be truthfully ascribed factive rational support in everyday contexts of epistemic appraisal, rational support contextualism can plausibly evade the concern we raised above regarding the standard attributer contextualist anti-sceptical strategy. In particular, on this view we can explain why the underdeterminationbased sceptical challenge doesn't go through, since in everyday contexts of epistemic appraisal subjects can be truthfully ascribed rational support which is strong enough to conflict with $\left(\mathrm{S}_{2} 1\right)$. Thus the underdetermination principle can hold and yet radical scepticism can nonetheless be resisted. Moreover, this view brings with it the usual advantage of attributer contextualist accounts, in that it can explain why radical scepticism can seem so compelling. After all, on this proposal radical scepticism is in a sense entirely correct, in that relative to contexts of epistemic appraisal in which radical sceptical error-possibilities are at issue assertions of knowledge ascription sentences will tend to express falsehoods. Rational support contextualism thus has advantages relative to attributer contextualism when it comes to dealing with the radical sceptical problem.

Nonetheless, there are a number of problems with rational support contextualism, many of them shared with standard versions of attributer contextualism. First, like attributer contextualism, there is the worry that it is too simple a solution to the problem in hand. Recall that the attributer contextualist treatment of radical scepticism invited the response that if this problem simply trades on a raising of the epistemic standards applicable to the evaluations of knowledge ascription sentences, then surely this is something that we would have spotted long before now. Could we really have been so ignorant about how such a central term as 'knows' functions? The same kind of worry surfaces with regard to rational support contextualism. If the extent of the rational support one's beliefs enjoy is straightforwardly responsive to contextual factors in this way, such that the problem of radical scepticism turns on this kind of contextsensitivity, then isn't this something that we would have realised long ago?

A second problem that rational support contextualism shares with attributer contextualism concerns how it endorses an epistemic hierarchy of contexts. Recall that attributer contextualism concedes that radical scepticism, qua position, is correct rela- 
tive to the high epistemic standards that are operative in sceptical contexts of epistemic appraisal. Rational support contextualism makes a comparable claim, albeit this time with regard to the rational support available for our beliefs. But doesn't this effectively cede the epistemic high ground to radical sceptic, such that if only we were thoroughgoing in our epistemic evaluations, then we would be-quite properly-led to sceptical conclusions? The crux of the matter is that what we ideally want from a response to radical scepticism is a way of showing that there is something inherently illegitimate about the sceptical context of epistemic evaluation, such that it is deprived of the epistemic high ground. This is not something that either attributer contextualism or rational support contextualism can offer, however.

A further problem facing rational support contextualism as an anti-sceptical proposal concerns the dialectical effectiveness of the appeal to contexts of epistemic appraisal. For notice that the anti-sceptical work is in fact done by the claim that relative to everyday contexts of epistemic appraisal agents can be properly said to be in possession of factive rational support for their beliefs. But if we can make sense of this idea at all, then why do we need to appeal to contexts of epistemic appraisal, at least as far as underdetermination-based radical scepticism goes? After all, this idea all by itself will block this form of radical scepticism, since it is in direct opposition to $\left(S_{2} 1\right)$. So what is added by the appeal to contexts of epistemic appraisal?

The rational support contextualist will no doubt contend that the contextualist element of the view is required in order for the proposal to have diagnostic appeal. The thought would be that without this aspect of the thesis there is not a plausible story in play regarding why the radical sceptic's assertions about our epistemic position can initially strike us as true. But we have already noted some deficiencies in the diagnostic element of the view, so this consideration is hardly decisive. Moreover, the relevant contrast is not merely with a (non-contextualist) view which allows factive rational support but which does not in addition offer any further anti-sceptical diagnostic story. Rather, the contrast is with such an alternative view when allied to its own anti-sceptical diagnostic story.

There is indeed such a proposal in the literature, what is known as epistemological disjunctivism. ${ }^{17}$ This endorses the idea that our perceptual knowledge is paradigmatically supported by factive reasons (without appealing to any riders regarding contexts of epistemic appraisal), while also offering a detailed account both of why such a proposal is philosophically sound (contrary to the prevailing wisdom) and how it is rooted in our everyday practices. The upshot is an undercutting response to underdetermination-based radical scepticism that argues that this puzzle only seems like a paradox because it illicitly trades on dubious philosophical theses which run counter to epistemological disjunctivism and, thereby, our everyday epistemic practices.

If epistemological disjunctivism is a cogent position to hold, then rational support contextualism is on very thin ground indeed. On the one hand, epistemological disjunctivism incorporates the very element-i.e., the notion of factive reasons - that enables rational support contextualism to resist $\left(S_{2} 1\right)$, without being in addition committed to

17 This proposal is rooted in the work of McDowell (e.g., 1995). See Pritchard (2008, 2012a, 2015, part three) for a recent articulation and defence of this thesis. 
any further contextualist thesis. ${ }^{18}$ On the other hand, this proposal also avoids making the kinds of concession to radical scepticism that we have just seen to be problematic. According to this view, after all, the sceptic doesn't occupy a privileged epistemic position at all-i.e., one in which more demanding epistemic standards are applicable — but is rather simply trading on a philosophical error that should be corrected.

One way that the rational support contextualist can respond to this line of objection is to point out that while epistemological disjunctivism might have dialectical advantages when it comes to underdetermination-based radical scepticism, the overall dialectical situation alters back into their favour once we also factor in closure-based radical scepticism. The reason for this is that if one straightforwardly applies epistemological disjunctivism to closure-based radical scepticism, then it seems to entail that one not only has factive rational support for one's everyday rationally supported knowledge, but that one also, via closure-based inferences, has factive rational support for one's rationally-grounded knowledge that one is not the victim of radical scepticism hypotheses. And yet that seems manifestly epistemically immodest, and fails to account for our strong intuition that there is something inherently dubious about the idea that we can know the denials of radical sceptical hypotheses at all (much less in virtue of factive rational support). ${ }^{19}$

In contrast, according to rational support contextualism, the context of epistemic appraisal in which radical sceptical hypotheses are raised is one in which factive rational support is no longer properly attributable, and hence ascriptions of knowledge in this context will tend to express falsehoods. As a result, this proposal can avoid making the kind of unduly bold anti-sceptical claim that the epistemological disjunctivist seems committed to. Rational support contextualism is thus on this front at least epistemically modest, and hence seems to be on stronger ground than epistemological disjunctivism when it comes to closure-based radical scepticism.

\section{Two sources of scepticism}

Let's review where we are. We have noted the implausibility of attributer contextualism as an anti-sceptical strategy, particularly as regards underdetermination-based radical scepticism. We have also seen that rational support contextualism fares much better, but that it is also faces the challenge of explaining why it is to be preferred to the alternative anti-sceptical position offered by epistemological disjunctivism. That challenge can be somewhat blunted, however, by the observation that while epistemological disjunctivism has dialectical advantages over rational support contextualism when it comes to underdetermination-based radical scepticism, the dialectical situation is reversed once we turn our attentions back to closure-based radical scepticism.

I think that in order to chart a path through this debate it is crucial that we recognise not just that the sceptical problem we are considering has two logically distinct

\footnotetext{
18 I explore in detail what the epistemological disjunctivist should say about the new evil demon intuition in Pritchard (forthcoming $b$ ).

19 See Pritchard (2008, 2012a, part three) for a defence of the idea that epistemological disjunctivism can be applied to the closure-based formulation of radical scepticism. But see also Pritchard (2015, part three) for the concession that such an application is, at best, philosophically awkward.
} 
formulations, but also that these two formulations reflect distinct sources of scepticism. Only with this claim in play will we understand why a common solution to both formulations of the problems-whether via epistemological disjunctivism, rational support contextualism, or some other proposal-is unlikely. Moreover, we will gain a purchase on what the shape of an adequate response to both sceptical problems will look like.

Let's begin with closure-based scepticism. This arises out of a commitment to what we might term the universality of rational evaluation, where this involves the thought that there are no in principle limitations on the scope of rational evaluation. This commitment is revealed in the fact that via closure-based inferences we can, it seems, harmlessly shift our focus from local rational evaluations to global rational evaluations, as when we query the rational basis of our hinge commitments. Underdeterminationbased scepticism, in contrast, is concerned with what we might term the insularity of reasons, where this is the claim that the rational support that our beliefs enjoy, even in the best case, can be no better than the rational support enjoyed by our envatted counterparts. It is only with this commitment in play that the underdetermination principle can generate the advertised sceptical conclusion. ${ }^{20}$

I have argued elsewhere that we should reject both of these underlying claims. ${ }^{21}$ What is important for our present purposes, however, is that the way in which one motivates a denial of these claims is very different, as reflecting the fact that they are distinct sceptical sources leading to logically distinct formulations of the sceptical problem. It should be clear that epistemological disjunctivism and rational support contextualism are committed to rejecting the insularity of reasons thesis. Neither of these views involves denying the universality of rational evaluation thesis, however. This puts epistemological disjunctivism into a tricky position, since it is obliged, via closure, to endorse the epistemically immodest thesis that one can know the denials of sceptical hypotheses on a factive rational basis. Rational support contextualism fares better on this score, since it isn't committed to this epistemically immodest conclusion. But this also comes at a price, since it involves ceding the legitimacy of the sceptic's universal rational evaluations, and thereby also ceding to her the epistemic high ground. Is there not a better way out of this bind?

I think there is, and that it lies in also rejecting the universality of rational evaluation thesis. Indeed, I claim that Wittgenstein-in his final notebooks, published as $O n$ Certainty (1969) — offers us a philosophical basis on which to undertake this move. I don't have space to articulate this proposal at length here, but let me at least sketch out the bare essentials of the view. Wittgenstein argues that it is in the very nature of a rational evaluation that it takes place against a background of a framework of basic commitments that are essentially arational. These hinge commitments, as they are known, embody one's fundamental certainty that one is not radically and fundamentally mistaken in one's beliefs. Wittgenstein contends that it is essential to being a rational subject-i.e., someone who undertakes rational evaluations, who inquires,

\footnotetext{
20 For further discussion and defence of the idea that closure-based radical scepticism and underdetermination-based radical scepticism are logically distinct, and that they reflect two distinct sources of scepticism, see Pritchard (2015, part one). See also Pritchard (2005a, part one; 2005b, 2016).

21 See especially Pritchard (2015). See also Pritchard (2016).
} 
who doubts, and so on-that one has these hinge commitments. If that's right, then this counts squarely against the universality of rational evaluation thesis.

Does this mean that Wittgenstein is committed to rejecting the closure principle? Interestingly, I don't think this follows at all. This is because of the special kind of propositional attitude that Wittgenstein has in mind when it comes to our hinge commitments. He argues that this is a 'primitive', 'animal', 'visceral' conviction, one that is neither acquired via rational processes nor in principle responsive to rational considerations. But if that's right, then whatever this propositional attitude is, it is not the kind of propositional attitude that epistemologists are interested in when they are concerned with rationally grounded knowledge. That is, it is not a belief, at least in the sense of belief such that it is a constituent of rationally grounded knowledge. ${ }^{22}$ Crucially, however, the closure principle essentially involves the acquisition of a belief (i.e., that one is not the victim of a radical sceptical hypothesis) in just this sense via the paradigmatically rationally process of competent deduction. It follows that closure is simply inapplicable to our hinge commitments on at least two fronts, in that one cannot form beliefs in a hinge commitment in the relevant sense, much less form such a belief on the basis of a rational process.

This point is important since it highlights the non-revisionary aspect of Wittgenstein's proposal. The closure principle turns out to be unproblematic. What is problematic is rather the conjunction of this principle with the universality of rational evaluation thesis. Only with these two theses combined can one generate the closurebased sceptical paradox, since only then can one employ closure to draw inferences regarding radical sceptical hypotheses. Put another way, the putative inconsistent triad that we offered above with regard to closure-based scepticism is in fact not inconsistent at all, as one can endorse all three claims without contradiction so long as one rejects the universality of rational evaluation thesis. Where the closure-based radical sceptical paradox goes awry is with regard to the bridging claim that is meant to be derived from the closure principle (i.e., $\left(\mathrm{S}_{1} 2\right)$ ), since it turns out that closure alone is not sufficient to derive this claim, as one also needs the universality of rational evaluation thesis too. In this way, Wittgenstein is offering us an undercutting response to closure-based radical scepticism that demonstrates that this is in fact a pseudo-problem, in that it essentially turns on an appeal to a philosophical thesis that has been shown to be false. ${ }^{23}$

In any case, the point of the foregoing has not been to convince the reader of the merits of the Wittgensteinian approach to closure-based scepticism, but rather just to explain what such a proposal amounts to. Note, however, that this approach to scepticism gains no purchase at all on underdetermination-based radical scepticism. For instance, that it is in the nature of rational evaluations that they are essentially local is entirely compatible with the idea that all rational support is by its nature insular.

\footnotetext{
22 There are, of course, many notions of belief operative in the philosophical literature. See, for example, Stevenson (2002) for a recent taxonomy of different kinds of belief. It is thus important to my claim that our hinge commitments are not beliefs that I have a particular notion of belief in mind (i.e., that propositional attitude which is meant to be a constituent of rationally grounded knowledge).

23 For further defence of this particular rendering of Wittgenstein's proposal regarding the structure of rational evaluation, see Pritchard (2012b, 2015, part two). For two recent surveys of the contemporary literature on hinge epistemology, see Pritchard (2011; forthcoming a).
} 
There is thus no straightforward route from the rejection of the universality of rational evaluation thesis to a rejection of the insularity of reasons thesis. Given the logical differences between these two formulations of the sceptical problem that we noted above, this is hardly surprising. But if we do not expect a Wittgensteinian rejection of the universality of rational evaluation thesis to offer us a solution to underdeterminationbased scepticism, then why should we expect an anti-sceptical proposal that is targeted at underdetermination-based scepticism, such as epistemological disjunctivism, to be applicable to the closure-based formulation of the problem?

Here is the crux: epistemological disjunctivism and the Wittgensteinian account of the structure of rational evaluation are natural philosophical bedfellows. If one weds the former to the latter, then one has a response to underdetermination-based radical scepticism (via a rejection of the insularity of reasons thesis) that is not committed to epistemic immodesty when it comes to closure-based radical scepticism. This is because although one can have factive rational support for one's everyday beliefs, one cannot convert such factive support, via a closure-style inference, into factive rational support for one's hinge commitment that one is not the victim of radical sceptical hypotheses. And, going in the other direction, if one weds the latter to the former, then one has a response to closure-based radical scepticism (via a rejection of the universality of reasons thesis) that can also handle underdetermination-based radical scepticism. On this view, while all rational evaluations are essentially local, it is nonetheless also the case that one's everyday beliefs can be in the market for factive rational support, contra the insularity of reasons thesis.

If I am right that the sceptical problem trades on two distinct sources of sources of scepticism, reflected in the fact that it generates two logically distinct formulations, then it is hardly surprising that an adequate solution to this problem will require a double-faceted-or biscopic, as I have elsewhere described it-response. ${ }^{24}$ Indeed, we should expect that any attempt to derive a response to both formulations of the sceptical problem from a single anti-sceptical thesis is bound to generate awkward philosophical consequences. We can see this point at work if we return to the status of rational support contextualism. This had dialectical advantages over epistemological disjunctivism insofar as the latter was applied to both underdetermination and closurebased formulations of the problem. But this dialectical advantage clearly disappears if one allies disjunctivism to a Wittgensteinian account of the structure of rational evaluation. And that of course means that the body of difficulties previously raised for rational support contextualism now rears its head once more, not least the charge that such a proposal effectively cedes the epistemic higher ground to the radical sceptic. Far better, I suggest, to reject the universality of rational evaluation thesis altogether and cut off this version of the sceptical problem at source. Only then will we gain an adequate response to the problem of radical scepticism, in both of its guises. ${ }^{25}$

\footnotetext{
24 See especially Pritchard (2015, part four). See also Pritchard (2016).

25 Thanks to Stefano Cossara, Jean-Baptiste Rauzy, and Xiaoxing Zhang. I am also grateful to two anonymous reviewers from Synthese for their reports on an earlier version of this paper.
} 
Open Access This article is distributed under the terms of the Creative Commons Attribution 4.0 International License (http://creativecommons.org/licenses/by/4.0/), which permits unrestricted use, distribution, and reproduction in any medium, provided you give appropriate credit to the original author(s) and the source, provide a link to the Creative Commons license, and indicate if changes were made.

\section{References}

Cohen, S. (1984). Justification and truth. Philosophical Studies, 46, 279-296.

Cohen, S. (2000). Contextualism and skepticism. Philosophical Issues, 10, 94-107.

DeRose, K. (1995). Solving the skeptical problem. Philosophical Review, 104, 1-52.

Dretske, F. (1970). Epistemic operators. Journal of Philosophy, 67, 1007-1023.

Dretske, F. (2005a). The case against closure. In E. Sosa \& M. Steu (Eds.), Contemporary debates in epistemology (pp. 13-26). Oxford: Blackwell.

Dretske, F. (2005b). Reply to Hawthorne. In E. Sosa \& M. Steup (Eds.), Contemporary debates in epistemology (pp. 43-46). Oxford: Blackwell.

Hawthorne, J. (2005). The case for closure. In E. Sosa \& M. Steup (Eds.), Contemporary debates in epistemology (pp. 26-43). Oxford: Blackwell.

Lehrer, K., \& Cohen, S. (1983). Synthese. Justification, Truth, and Coherence, 55, 191-207.

Lewis, D. (1996). Elusive knowledge. Australasian Journal of Philosophy, 74, 549-567.

McDowell, J. (1995). Knowledge and the internal. Philosophy and Phenomenological Research, 55, 877893.

Neta, R. (2002). S Knows that P. Noûs, 36, 663-689.

Neta, R. (2003). Contextualism and the problem of the external world. Philosophy and Phenomenological Research, 66, 1-31.

Nozick, R. (1981). Philosophical explanations. Oxford: Oxford University Press.

Pritchard, D. H. (2001). Contextualism, scepticism, and the problem of epistemic descent. Dialectica, 55, 327-349.

Pritchard, D. H. (2005a). Contextualism, scepticism and warranted assertibility manœuvres. In J. KeimCampbell, M. O’Rourke, \& H. Silverstein (Eds.), Knowledge and skepticism (pp. 85-104). Cambridge: MIT Press.

Pritchard, D. H. (2005b). Epistemic luck. Oxford: Oxford University Press.

Pritchard, D. H. (2005c). The structure of sceptical arguments. Philosophical Quarterly, 55, 37-52.

Pritchard, D. H. (2008). McDowellian neo-Mooreanism. In A. Haddock \& F. Macpherson (Eds.), Disjunctivism: Perception, action, knowledge (pp. 283-310). Oxford: Oxford University Press.

Pritchard, D. H. (2011). Wittgenstein on scepticism. In O. Kuusela \& M. McGinn (Eds.), Oxford Handbook on Wittgenstein (pp. 521-547). Oxford: Oxford University Press.

Pritchard, D. H. (2012a). Epistemological disjunctivism. Oxford: Oxford University Press.

Pritchard, D. H. (2012b). Wittgenstein and the groundlessness of our believing. Synthese, 189, $255-272$.

Pritchard, D. H. (2015). Epistemic angst: Radical skepticism and the groundlessness of our believing. Princeton: Princeton University Press.

Pritchard, D. H. (2016). Epistemic Angst. Philosophy and Phenomenological Research. doi:10.1111/phpr. 12280 .

Pritchard, D. H. (Forthcoming a). Wittgenstein on hinges and radical scepticism in on certainty. In H.-J. Glock \& J. Hyman, (Eds.), Blackwell Companion to Wittgenstein. Oxford: Blackwell.

Pritchard, D. H. (Forthcoming b). Shadowlands. In F. Dorsch \& J. Dutant, (Eds.), The new evil demon: New essays on knowledge, justification and rationality. Oxford: Oxford University Press.

Rysiew, P. (2011). Contextualism. In S. Bernecker \& D. H. Pritchard (Eds.), Routledge companion to epistemology (pp. 523-535). London: Routledge.

Schiffer, S. (1996). Contextualist solutions to skepticism. Proceedings of the Aristotelian Society (new series), 96, 317-333.

Stanley, J. (2005). Knowledge and practical interests. Oxford: Clarendon Press.

Stevenson, L. (2002). Six levels of mentality. Philosophical Explorations, 5, 105-124.

Vogel, J. (1990). Cartesian skepticism and inference to the best explanation. Journal of Philosophy, 87, 658-666.

Wittgenstein, L. (1969). In D. Paul \& G. E. M. Anscombe (Eds.) On Certainty (E. M. Anscombe, G. H. von Wright, Trans.). Oxford: Blackwell. 